\title{
DESCENTRALIZAÇÃO E FINANCIAMENTO DA EDUCAÇÃO BRASILEIRA: UMA ANÁLISE COMPARATIVA, 1930-1964
}

\author{
ThOMAS H. KANG* \\ FEA/USP, ESPM-Sul
}

Submetido em Agosto 2010; aceito em Junho 2011

\begin{abstract}
Resumo
Entre 1930 e 1964, um período de rápido crescimento econômico no Brasil, a expansão do ensino primário foi muito aquém do suficiente para superar o relativo atraso educacional. Este artigo sustenta não apenas que houve pouco interesse dos governos, como também que a estrutura administrativa e de financiamento da educação primária foi também responsável pela manutenção do atraso. A administração do ensino primário era de responsabilidade estadual, mas o governo federal, que detinha grande parte da receita tributária, não financiava adequadamente os estados. A comparação com o caso dos Estados Unidos parece apoiar as conclusões desse trabalho.
\end{abstract}

\section{Palavras-Chave}

história econômica, descentralização, financiamento da educação, capital humano

\section{Abstract}

From 1930 to 1964, when the Brazilian economy was growing rapidly, the expansion of primary schooling was far from sufficient to overcome the Brazilian comparative educational backwardness. This paper shows that not only there was little interest of governments in expanding schools, but also that administrative and financial structures of primary schooling were responsible for sustaining that backwardness. State governments were responsible for the administration of primary schools, but did not have enough financial resources. The federal government, which had a huge part of the tax revenues, did not transfer enough financial resources to the states. Comparing the Brazilian case to that of the United States seems to support our conclusions.

JEL classification codes: N36, I22

Keywords: economic history, decentralization, educational finance, human capital

\footnotetext{
* Mestre em Economia pelo IPE-FEA-USP e Professor Assistente da Escola Superior de Propaganda e Marketing (ESPM-Sul), Porto Alegre - Endereço para contato: Rua Guilherme Schell, 350 - Santo Antônio - CEP 90.040-000 Email: kang.thomas@gmail.com / tkang@espm.br

Artigo baseado no quarto capítulo de minha dissertação de mestrado intitulada "Instituições, Voz Política e Atraso Educacional no Brasil, 1930-1964". Agradeço principalmente a Renato Perim Colistete, por revisões, críticas, comentários e por toda a orientação ao longo do período. Agradeço também aos membros da banca, Dante Mendes Aldrighi e William Roderick Summerhill por todas as sugestões e críticas. Por último, agradeço à $\mathrm{CNPq}$ e FAPESP.
} 


\section{Introdução}

Embora o atraso educacional fosse percebido há muito tempo pelos políticos brasileiros, houve pouco esforço ao longo das décadas para melhorar a situação educacional do país, principalmente nos níveis básicos de ensino. Embora tenham ocorrido avanços na educação, esse progresso foi insuficiente durante o período 1930-1964 para tirar o Brasil da situação de atraso frente a outros países, incluindo os vizinhos latino-americanos. Os governos Dutra e Goulart demonstraram maior preocupação com a situação do ensino primário, embora os avanços tenham sido limitados. As declarações ministeriais na época do governo Kubitschek foram bastante eloquentes quanto à prioridade da alocação de recursos para o ensino secundário e superior (Kang, 2009, 2010; Pires, 1996).

Nesse período de forte crescimento econômico (média de 5,6\% a.a. entre 1930 e 1964), o Brasil apresentou persistentemente um dos piores índices educacionais na América Latina: em 1950, 49\% da população acima dos 15 anos era analfabeta (Astorga; Bergés; Fitzgerald, 2005). Enquanto isso, países latino-americanos como Argentina, Costa Rica e Chile estavam muito à frente do Brasil em termos educacionais, assim como países como a Coreia do Sul, que posteriormente apresentou enorme crescimento econômico (Barro; Lee, 2000). Não obstante tenha mantido altos índices de crescimento até o final dos anos 1970, o Brasil entrou em um longo período de estagnação na década de 1980, mantendo um perfil de distribuição de renda extremamente concentrado (em 1978, o índice de Gini era de 0,604, considerado bastante alto), o que possivelmente também é relacionado a carências nos níveis básicos de ensino.

Ainda assim, embora a ação do governo federal tenha sido insignificante, os efeitos sobre a educação básica poderiam ter sido menos prejudiciais caso os governos estaduais ou locais tivessem atuado de forma diferente, uma vez que as Constituições delegaram essa função aos estados. No entanto, a atuação por parte dos estados e municípios foi bastante limitada, da mesma forma que a do governo federal. Uma das hipóteses para explicar a pouca efetividade da ação dos estados e municípios é de que a centralização tributária do governo no período 1930-1964 impediu que os governos estaduais e locais tivessem papel mais relevante. Dessa forma, as decisões federais eram de suma importância na determinação dos gastos em educação e na sua consequente expansão. Outra hipótese, porém, é que se o sistema tivesse sido mais descentralizado, a situação de atraso educacional poderia ter sido até pior, uma vez que os governos locais estariam mais sujeitos à captura por grupos locais poderosos. Recentemente, a literatura e os organismos multilaterais têm dado muita ênfase às vantagens da descentralização como uma condição importante para melhora da oferta de diversos serviços públicos, tais como educação pública básica (Burki; Perry; Dillinger, 1999; World Bank, 2000). A estrutura centralizada do financiamento educacional no Brasil teria sido um dos fatores 
responsáveis pelo atraso da educação no país, seguindo a lógica de uma das hipóteses apresentadas no parágrafo anterior. O Brasil, por exemplo, seguiu essa tendência de descentralização após a redemocratização no final dos anos 1980, com a delegação de responsabilidades maiores a estados e municípios. A Constituição de 1988 declarou, pelo menos legalmente, que aos municípios cabia a administração do ensino fundamental, ao contrário das Constituições anteriores que delegavam essa responsabilidade aos estados. ${ }^{1}$ Há, portanto, motivos suficientes para investigarmos a influência da descentralização no desempenho educacional do período.

É necessário, preliminarmente, definir o conceito de descentralização a ser utilizado. De acordo com Bardhan e Mookherjee (2006, p. 4-5), há três conceitos básicos de descentralização: (i) administrativa, ou seja, autoridade sobre legislação e implementação de regulamentos locais, composição de gastos governamentais e fornecimento de serviços públicos; (ii) financeira, ou seja, autonomia na criação e coleta de impostos, na alocação de despesas relacionadas a serviços locais e também para pedir empréstimos a níveis superiores de governo ou ao mercado; e (iii) democrática, isto é, os governantes locais são eleitos pelos residentes locais ao invés de indicados por instâncias superiores de governo. No que podemos chamar de descentralização financeira, é necessário explicitar a diferença entre situações em que há descentralização do gasto público e casos em que há descentralização tanto em decisões de gasto como também na obtenção de receita.

Em um estudo sobre o atraso educacional brasileiro e suas consequências para o crescimento e o bem-estar da população, é necessário analisar qual foi o tipo de descentralização, e em que extensão ela se deu no que se refere à provisão e ao financiamento do ensino básico. Para podermos avaliar o caso brasileiro, é preciso entender quais são os possíveis efeitos da descentralização, aspecto que será tratado na segunda seção. Na terceira parte do trabalho, examinaremos o caso da educação primária norteamericana na virada do século XIX para o XX, época em que os Estados Unidos se tornaram os líderes educacionais, com o intuito de fazermos uma análise comparativa.

Destacaremos as características apontadas pela literatura como cruciais para a rápida expansão educacional norte-americana, em particular a descentralização administrativa e financeira, considerada um dos fatores principais. Em seguida, compararemos a estrutura brasileira com a norte-americana, visando levantar hipóteses que expliquem os motivos do atraso educacional brasileiro. A última parte está reservada para os comentários finais.

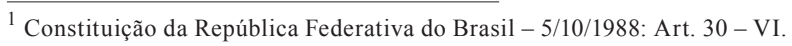




\section{Aspectos Teóricos e Empíricos da Descentralização}

Existem inúmeras análises teóricas sobre as vantagens e desvantagens da descentralização. Há também análises empíricas de políticas recentes no Brasil e na Índia, as quais revelam que os efeitos da descentralização podem apresentar diferentes resultados em diferentes regiões (Baiocchi, 2005; Chaudhuri, 2005). Tendler (1997), por exemplo, mostra que em estados como o Ceará, a descentralização dos serviços de saúde pública resultou em pior desempenho na provisão. Por outro lado, Santos (1998) argumenta que houve grande melhora em taxas de matrícula e acesso a saneamento básico a partir da experiência de descentralização em Porto Alegre com o chamado "orçamento participativo". De acordo com a literatura, os resultados são ambíguos, mostrando que a preponderância de efeitos positivos depende do contexto em que estruturas descentralizadas são implementadas (Bardhan, 2002). Revisaremos a seguir as principais conclusões da literatura a respeito do tema.

\section{A. Possíveis Vantagens da Descentralização}

Grande parte da ênfase dada por organismos multilaterais à adoção de estruturas descentralizadas tem relação com as vantagens que governos locais detêm em aspectos informacionais, uma vez que estão mais próximos dos locais onde são oferecidos os serviços públicos. Os primeiros trabalhos, como Oates (1972), enfatizavam que assumindo a existência de preferências heterogêneas entre diversas regiões e na ausência de spillovers (transbordamentos), haveria justificativa teórica para adoção de um sistema descentralizado. O motivo seria que a razão de ser de um sistema descentralizado é que o consumo dos bens e serviços oferecidos estariam confinados à jurisdição do governo local - por isso, era preciso assumir preferências heterogêneas e ausência de transbordamentos. Trabalhos posteriores, como o de Tommasi e Weischelbaum (1999), chamaram atenção para questões relacionadas à informação e accountability. Para esses autores, quanto maior a jurisdição dos governos, a conexão entre pagamento pelos serviços públicos e desempenho desses serviços se tornaria mais fraca devido à falta de accountability.

No caso da educação, King e Özler (1998) sustentam que a descentralização administrativa de algumas tarefas na Nicarágua, que foram transferidas do governo central para conselhos locais com envolvimento de pais, teve impacto positivo sobre o desempenho dos alunos nos locais onde houve maior autonomia. Probe (1999) afirma que as instituições de accountability locais não são fortes no norte da Índia, onde se verificam problemas na provisão de serviços relacionados à saúde e educação. O resultado surpreendente é que o desempenho educacional local na China, que vive sob regime autoritá- 
rio, é melhor do que em muitas partes da Índia, democrática desde sua independência (Drezè; Saran, 1995). O mesmo poderia ser dito sobre a provisão educacional em Cuba e os resultados piores de outros países latino-americanos. A razão desses fenômenos seria a existência de instituições locais de accountability (Bardhan, 2002, p. 201).

Embora a democracia possa ajudar a criar instituições que respondam melhor às demandas da população, ela não é suficiente para garantir a provisão adequada de serviços públicos. Lindert (2003) caracteriza a Índia como um país que, embora com eleições livres, não deu oportunidades de voz política a significativa parte de sua população ao longo da história - o que teria refletido no elitismo da política educacional indiana, que muito favoreceu o ensino superior. Evidentemente, há vários casos, como nota Bardhan (2002, p. 201-2), de países autoritários onde não existem instituições que garantem provisão adequada de serviços públicos e onde, consequentemente, a situação é muito pior do que no norte da Índia.

Os exemplos de alguns países autoritários que conseguiram desempenho relativamente superior na provisão de serviços públicos ao de países como a Índia são coerentes com a tese de Lindert acerca da expansão escolar alemã no século XIX. Muito embora a Alemanha de Bismarck não possuísse instituições democráticas formais com direito de voto, havia instituições que permitiam a participação de segmentos amplos da população em questões relacionadas à educação. Da mesma forma que os Estados Unidos, que sempre contou com direito de voto em nível local, a Alemanha foi líder em escolaridade básica por conta dessas instituições. Ou seja, a descentralização alemã em questões educacionais no período bismarckiano (considerado centralizado em muitos aspectos políticos) teria sido um fator positivo crucial para o excepcional resultado em termos de escolaridade, uma vez que aumentou a voz política da população (Lindert, 2004). Ademais, o sistema norte-americano de educação também se caracterizou por intensa descentralização em sua fase de expansão, tanto do primário quanto do secundário (Lindert, 2004; Goldin; Katz, 2008).

\section{B. Possíveis Desvantagens da Descentralização}

Embora os problemas locais tendam a ser mais bem identificados pelos governos locais, além da cobrança política tornar-se maior, há também aspectos negativos que podem advir da descentralização. Se as elites locais detêm grande parte do poder político, é possível que a descentralização resulte em políticas direcionadas à própria elite e, consequentemente, em detrimento do resto da população. Esse é o caso da chamada captura do governo por grupos de interesse. 
Pode haver captura tanto do governo central como do governo local. Quando há captura simultânea de ambos, a descentralização tenderá a aumentar a eficiência e a equidade na provisão de serviços públicos caso o governo local seja igualmente ou menos capturado que o central. ${ }^{2}$ Todavia, ineficiência e desigualdade podem ser os resultados quando o desproporcional poder das elites locais captura o governo local em níveis maiores do que o governo central (Bardhan, 2002, p. 194; Bardhan; Mookherjee, 2000). A extensão da captura depende da desigualdade dentro das comunidades, tradições de participação política, consciência dos votantes, regularidade e transparência dos pleitos, efetividade da mídia, além de transparência nos processos decisórios e nas contas governamentais locais (Bardhan, 2002, p. 194).

Alguns estudos demonstram que o desempenho de certos programas pode ser pior em locais onde há maior desigualdade fundiária, como mostrado por Galasso e Ravaillon (2001) para o caso de Bangladesh (food for education). No entanto, não há evidências de que o governo central seja mais sujeito a pressões da população, uma vez que o direcionamento do programa dentro das comunidades foi mais intenso do que o verificado entre comunidades. O sucesso da descentralização, portanto, depende da concentração de poder político local. A descentralização financeira e administrativa, como sustenta Lindert (2004, p. 104-105), é interessante em uma fase inicial da expansão educacional porque nas localidades em que a distribuição do poder político é mais igualitária, as demandas de um segmento maior da população tendem a ser levadas em conta na implementação de políticas públicas. Se houver algumas localidades com essa característica, haverá melhora nos serviços públicos dessas regiões, sendo a descentralização um instrumento para se atingir resultados mais eficientes, ainda que indiferentes à distribuição regional. Esse é o outro lado da moeda: a tendência é de aumento das desigualdades regionais com a persistência de um sistema descentralizado. Se, além de eficiência, a equidade for levada em conta, a solução centralizadora em uma fase posterior à descentralização pode levar a resultados mais eficientes e equitativos, uma vez que a política central pode estimular as regiões atrasadas a atingir os níveis apresentados pelas regiões mais progressistas - que apresentaram melhora na primeira fase. Evidentemente, o sucesso dessa segunda fase depende do grau de captura do poder central, que pode ser expressivo caso as regiões atrasadas contem com elites influentes na política nacional.

\section{O Caso dos Estados Unidos}

$\mathrm{Na}$ seção anterior, analisamos as possíveis vantagens e desvantagens de um sistema descentralizado. De acordo com a literatura, uma das grandes virtudes do bem-sucedido

\footnotetext{
${ }^{2}$ Captura no mesmo nível dos governos local e central geraria melhor provisão dos serviços oferecidos pelo governo local devido a maior proximidade entre população e governo local.
} 
sistema educacional dos Estados Unidos no início de sua expansão foi justamente o seu caráter descentralizado. Por esse motivo, é particularmente útil estudarmos a história da expansão educacional norte-americana para avaliar o caso brasileiro.

No Brasil, a expansão educacional, em termos quantitativos, atingiu taxas brutas de matrícula no primário de 98\% apenas na década de 1990, enquanto países como Argentina, por exemplo, registravam 97\% de crianças matriculadas na década de 1950 (Frankema, 2008, p. 215). ${ }^{3}$ Além disso, se observarmos as taxas de alfabetização, veremos que em 1950 o Brasil apresentava taxa de 49,3\%, enquanto Argentina e Estados Unidos estavam muito à frente ( $88 \%$ e 97\% respectivamente). Mesmo em 2000, o Brasil ainda não havia alcançado a taxa argentina de 1950 , uma vez que apenas $85 \%$ da população era alfabetizada: situação pior que a da Bolívia (86\%) (Bergès, 2009, p. 28).

Portanto, é necessário perguntar por que motivo a expansão do primário não ocorreu anteriormente. Por um lado, as políticas nacionais de ensino preocuparam-se pouco com o ensino básico, tendendo a privilegiar de forma consciente e explícita a aplicação de recursos no ensino superior (Kang, 2010). No entanto, sabemos que era atribuição constitucional dos estados a provisão de ensino primário. A descentralização em nível local ou municipal poderia ocorrer a critério dos estados.

De acordo com a literatura sobre a história econômica da educação, a descentralização é fator fundamental para explicar o avanço educacional em diversos países. Ela é apontada como um dos fatores fundamentais da expansão educacional norte-americana segundo, por exemplo, Goldin e Katz (2008) e Lindert (2004). Ademais, outras características além da descentralização também podem ter impacto sobre o avanço educacional de nível básico, o que também é mostrado pelos estudos sobre história da educação nos Estados Unidos. Goldin e Katz (2008) apontam os fatores que teriam sido essenciais para que os Estados Unidos fossem os líderes mundiais em educação na virada do século XX. É preciso notar que, conforme os autores, os fatores listados a seguir são positivos dependendo do contexto, ou seja, não independem de tempo e espaço. Os fatores que teriam estimulado a expansão educacional nos EUA seriam: (a) descentralização administrativa, ou seja, distritos ou governos locais eram responsáveis pela provisão dos serviços; (b) descentralização financeira, tanto em aspectos tributários como também nos gastos; (c) neutralidade em relação a gênero; (d) educação secular, no sentido de que não havia sectarismo nem concessão de subsídios públicos para escolas confessionais; e (e) sistema aberto e menos rígido, que não punia demasiadamente o mau desempenho passado dos alunos, facilitando a posterior recuperação (Goldin; Katz, 2008, cap. 4).

\footnotetext{
${ }^{3}$ Os dados de Maduro (2007) afirmam que o Brasil já teria atingido taxa de matrículas no primário de $97 \%$ na década de 1980. Isso não muda o fato de que houve substancial atraso educacional no Brasil em relação à Argentina.
} 
Ainda, segundo Goldin e Katz, a partir da segunda metade do século XIX até as primeiras décadas do século $\mathrm{XX}$, teriam sido os fatores mencionados acima os responsáveis pela expansão educacional americana em moldes democráticos e igualitários.

Como notado antes, os autores enfatizam que tais fatores não são necessariamente positivos em qualquer contexto, mas, naquele período, os sistemas europeus teriam apresentado características muito mais elitistas, explicando o atraso em número de matrículas em relação aos Estados Unidos (Goldin; Katz, 2008, cap. 4).

Para avaliar se a presença desses fatores (ou a falta deles) pode ter influenciado o caso brasileiro, devemos buscar uma solução para a questão relacionada ao contexto institucional levantada por Goldin e Katz: será que no contexto brasileiro do período democrático após o fim do Estado Novo, os fatores que teriam sido positivos para a expansão educacional norte-americana a partir de meados do século XIX teriam sido também positivos para o Brasil? Ou seja, se o sistema brasileiro tivesse sido mais descentralizado, aberto, secular e neutro em termos de gênero, teria havido melhora na educação primária? A explicação do atraso educacional brasileiro implica logicamente levantar essa questão contrafactual. ${ }^{4}$ Antes de responder essa pergunta, porém, é preciso descrever rapidamente o sistema escolar brasileiro em termos administrativos e financeiros para que possamos compará-lo ao sistema dos Estados Unidos. Com isso, podemos tentar identificar até que ponto os fatores que existiam nos Estados Unidos estavam ou não presentes e, a partir daí, sugerir hipóteses sobre os motivos do atraso educacional brasileiro.

\section{Descentralização Administrativa e Financeira no Brasil}

A literatura clássica costuma apontar o ano de 1930 como um divisor de águas na estrutura política do país. A Revolução de 1930, que levou Vargas ao poder, teria sido responsável por inovações como centralização, regulação, incentivos à iniciativa privada e participação ativa do Estado (Dulles, 1969; Ianni, 1971; Sodré, 1976; Skidmore, 1973; Suzigan, 1976). Há certo exagero nessa categorização. Topik (1980; 1987) mostra que o Estado era bem mais ativo e centralizado em muitos aspectos no período anterior a 1930 do que se supunha. Todavia, certamente houve maior centralização a partir da década de 1930, como mostram Fausto (1986) e Fonseca (1989).

A questão da educação também foi influenciada por esse movimento em direção à maior centralização, principalmente por conta da questão tributária. A centralização nesse

\footnotetext{
${ }^{4}$ Sobre o uso do contrafactual em história econômica não apenas como um tipo de análise válida, mas também como presente de forma implícita em qualquer tipo de explicação existente, ver Fogel (1964, 1967).
} 
quesito foi significativa, como veremos a seguir, e certamente influenciou as políticas educacionais do período, ainda que em termos administrativos houvesse alguma descentralização. No Brasil, o artigo 150 da Constituição de 1934 responsabilizou os estados pela provisão da educação primária pública, enquanto a União se encarregaria do ensino superior e de todos os níveis de ensino no Município Neutro, onde se encontrava a capital Rio de Janeiro. As demais Constituições não foram tão claras a respeito, mas seguiu-se esse padrão de atribuição de responsabilidades. Nos Estados Unidos, a educação primária esteve por um longo período a cargo de milhares de distritos escolares, cuja abrangência era submunicipal. Esses distritos escolares tinham liberdade para criar impostos e gastar seus recursos autonomamente em suas escolas.

Além dessas diferenças de jurisdição legal e administrativa, os níveis de governo nesses dois países possuíam distintas formas de financiamento. É importante vermos como eram financiados os gastos federais, estaduais e municipais no caso brasileiro, pois isso pode explicar em parte a incapacidade dos governos estaduais e municipais de arcar com os custos do ensino primário. Por não ser obrigação constitucional, a maioria dos estados tinha estruturas educacionais centralizadas. Alguns estados, como o Rio Grande do Sul, decidiram pela descentralização educacional em termos administrativos, mas mesmo os municípios desse estado careciam de independência financeira por conta da estrutura tributária do país. Veremos a seguir como eram financiados os níveis de governo e como eram os gastos em educação pública.

\section{A. Financiamento da Educação e Receita Tributária}

É possível avaliar a capacidade de financiamento da educação a partir da análise das fontes de receita dos governos estaduais no Brasil, responsáveis pela educação básica no país. Até a década de 1930, uma expressiva parte das receitas estaduais era oriunda da receita de exportações. Contudo, o imposto de exportação perdeu espaço paulatinamente até se tornar desprezível em termos percentuais: em 1930, 42,9\% da receita estadual eram originados do imposto sobre exportações; no ano seguinte, o percentual caiu para $29,0 \%$, chegando a $0,89 \%$ em 1958. O Imposto de Vendas e Consignações aos poucos foi se tornando a mais importante fonte de receita dos estados: embora representasse $1,0 \%$ da receita estadual em 1935, esse imposto já era o mais representativo da receita em 1947, alcançando a marca de $45,1 \%$ da receita estadual, cifra que atingiu 56,3\% em 1958 (Bueno; Pastore; Gitelman, 1962, p. XXI-XXV, p. 33-34). No Gráfico 1, é evidente a queda da importância do imposto de exportações e o crescimento vigoroso das receitas de Vendas e Consignações. 


\section{Gráfico 1 - Estrutura da Receita Tributária Estadual, Brasil, 1930-1958}

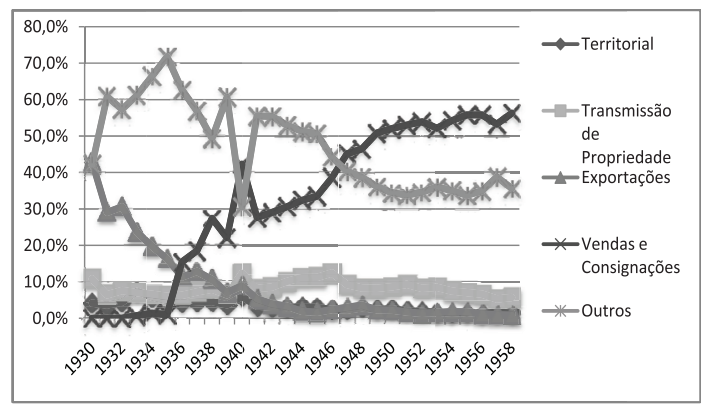

Fonte: Bueno, Pastore e Gitelman (1962).

No conjunto, como mostrado no Gráfico 2, a participação da receita tributária estadual manteve-se sempre entre $20 \%$ e $35 \%$ em relação à receita tributária total em todo o período apresentado pela figura. Os municípios apresentaram participação ainda menor na receita tributária total e com tendência declinante até 1984 , como também mostra o Gráfico 2. Com relação aos principais itens da receita tributária dos municípios, a participação dos três impostos municipais mais significativos (Indústrias e Profissões, Predial, de Licença e Territorial Urbano) esteve entre 40\% e 50\% entre o fim do Estado Novo em 1945 e o fim do período democrático em 1964. Como podemos ver no mesmo Gráfico 2, as fontes de receita municipais representavam uma parcela relativamente pequena $(5,8 \%$ na média entre 1936 e 2000) na receita tributária total do país. Ou seja, mais de $60 \%$ em média da receita tributária era de propriedade da União, o que indica elevada centralização fiscal.

Gráfico 2 - Receita Tributária no Brasil (União, Estados e Municípios), 1936-2000

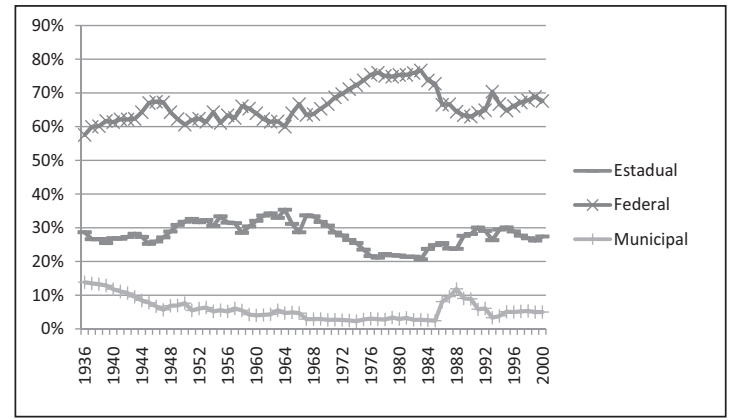

Fonte: IBGE. 
Como afirma Melchior (1981, p. 17-18), os municípios foram deixados na miséria financeira pela Constituição de 1934 (artigos 6, 8 e 13.2), o que não mudou significativamente com a Constituição de 1946 (artigo 29), nem com a Constituição de 1967 (artigo 25). Posteriormente, houve ainda maior centralização durante o regime militar. Durante a década de 1970, por exemplo, a proporção arrecadada pela União aumentou consideravelmente, chegando à marca dos 71,1\% em 1973.

Os problemas do excesso de centralização na arrecadação tributária foram constatados por autores que trataram do financiamento da educação, como Souza (1979, p. 18). Desde o Império, as diversas formas de tentar vincular a arrecadação a gastos com educação foram pouco frutíferas. De acordo com Melchior (1981), autor do mais completo trabalho sobre a história do financiamento da educação no Brasil, a primeira fonte de financiamento da instrução pública no Brasil foi o subsídio literário, criado na segunda metade do século XVIII. Até 1822, o subsídio literário foi a fonte quase exclusiva de financiamento da educação, que consistia em um imposto sobre carne verde e aguardente (Melchior, 1981, p. 27; Saviani, 2008, p. 99). Posteriormente, contou-se com outras fontes como, por exemplo, loterias e doações. A inspeção das escolas particulares gerava alguma receita através das multas aplicadas, as quais também eram revertidas para o ensino.

A partir de 1870, surgiram propostas de criação de taxas escolares, em um esforço de vincular recursos específicos a fins educacionais. De acordo com uma dessas propostas, inspiradas no modelo norte-americano, as províncias passariam a criar caixas escolares e tributos vinculados à educação. ${ }^{5}$ No entanto, sua implementação não foi bem-sucedida em muitos lugares como, por exemplo, em São Paulo, devido a problemas de regulamentação: a lei de 6/4/1887 criou o fundo, mas a principal fonte de financiamento, que era um novo imposto, não foi implementada. Os projetos de reforma da instrução pública da década de 1880, sendo o mais conhecido de autoria de Rui Barbosa, que também previa a criação de taxas escolares, agitaram os debates no Congresso, mas não foram aprovados. ${ }^{6}$ Como resultado, no fim do Império, o financiamento escolar continuava a depender, quase que exclusivamente, da receita geral de impostos (Melchior, 1981, p. 34-37).

\footnotetext{
${ }^{5}$ Tavares Bastos, ao propor a criação de taxas escolares, comparou o dispêndio educacional no Brasil com o dos Estados Unidos, concluindo que a criação de um novo tributo seria salutar para solucionar o atraso em relação aos norte-americanos (Melchior, 1981, p. 34 nota).

${ }^{6} \mathrm{O}$ projeto de reforma de ensino de Rui Barbosa previa inúmeras fontes de financiamento para a educação, entre as quais se destacavam os tributos sobre heranças e o imposto de capitação. Quanto à primeira, além da terça parte do produto das heranças vagas, havia tributos sobre a sucessão testamentária para parentes e estranhos (5\% e $10 \%$, respectivamente) e também um tributo de $50 \%$ sobre heranças destinadas a estabelecimentos religiosos. A outra fonte importante prevista era o imposto de capitação que consistia em dois mil réis por contribuinte residente na Corte e capitais provinciais, e de mil réis para outras localidades. Esses recursos seriam aplicados para construção e melhoramento de escolas, além de subsídio a escolas particulares leigas. É evidente a presença das ideias republicanas no projeto de reforma na questão das heranças para estabelecimentos religiosos e no subsídio a escolas seculares (Barbosa, 1883, Tomo IV, p. 133-135; Melchior, 1981, p. 36 nota 25).
} 
Após a mudança política com a Revolução de 1930, foram criados a Taxa de Educação e Saúde e o seu fundo correspondente, o Fundo Especial para Educação e Saúde, por meio do Decreto $n^{\circ} 21.335$ de 29/4/1932, sendo ambos de âmbito federal (Melchior, 1981, p. 39). A Taxa de Educação e Saúde incidia sobre qualquer documento mandatoriamente selado. Entretanto, por não ser ad valorem, esse imposto tornou-se pouco significativo diante do declínio do seu valor em termos reais. A taxa, que era de 200 réis (CR\$ 0,20) para cada documento, teve reajuste legal concedido somente em 1944 (CR\$ 0,40) e em 1946 (CR\$ 0,80), sendo posteriormente extinta em 1958.

Durante a década de 1930, algumas reivindicações da Escola Nova foram incorporadas na legislação. Uma delas foi a vinculação de recursos para a educação: os artigos 156 e 157 da Constituição de 1934 previram a vinculação de percentuais mínimos de receita para fins educacionais. Essa vinculação foi excluída na Carta de 1937, sendo retomada posteriormente com o retorno da democracia em $1946 .^{7}$

Antes do retorno ao regime democrático, contudo, criou-se em 1942 o Fundo Nacional do Ensino Primário (FNEP), assim como os equivalentes para os outros níveis de ensino em anos posteriores. O FNEP era financiado por um adicional de 5\% sobre o ICM incidente sobre bebidas alcoólicas (Souza, 1979, p. 19; Melchior, 1981, p. 48). O Fundo Nacional do Ensino Médio foi organizado em 1954 sem especificação de tributo determinado para financiá-lo, enquanto que o Fundo Nacional do Ensino Superior foi lançado somente em 1961.

As políticas de vinculação de receita da União foram ineficazes em geral, de acordo com Melchior (1981). Ainda segundo Melchior (1981, p. 61), estados e municípios sequer tentaram estruturar financeiramente a educação, embora educadores conhecidos como Anísio Teixeira (1956) já advogassem a articulação dos fundos em todos os níveis de governo e uma descentralização radical do sistema educacional. O grande problema era que, embora financeiramente não houvesse autonomia dos estados e municípios, previase que estes teriam autonomia administrativa. O diagnóstico de Melchior é preciso em relação à descentralização parcial e ineficaz existente:

Autonomia, delegação de autoridade e da responsabilidade são aspectos do processo de descentralização que só se conseguem com recursos financeiros. Com um sistema tributário que beneficia a União e os Estados, o máximo que podemos conseguir será a descentralização até o nível destes últimos. (Melchior, 1981, p. 67)

\footnotetext{
${ }^{7}$ A vinculação foi novamente suprimida na Constituição de 1967, redigida durante o regime militar.
} 
Em um país de enorme extensão geográfica como o Brasil, e também de acordo com a conceituação de Bardhan (2002), a autonomia estadual está longe de ser considerada descentralização. Além dos municípios terem poucos recursos, nem mesmo a parcela prevista pela Constituição para despesas com ensino primário era de fato realizada por muitos dos municípios. Mascaro (1954) nota que, para diversas cidades paulistas, o ensino primário aparece contemplado nos orçamentos municipais com parcela que mal ultrapassa metade da quota mínima de impostos destinada ao ensino. A municipalização foi posteriormente deixada de lado na LDB de 1961 após os inúmeros debates sobre o tema (Melchior, 1981, p. 69).

Por outro lado, os Estados Unidos apresentaram uma situação bastante diferente. Principalmente na fase da expansão da educação primária (segunda metade do século XIX), mas também na fase da expansão massiva do ensino secundário (entre 1910 e 1940), a estrutura das receitas era completamente distinta. O Gráfico 3 apresenta os dados de participação da receita tributária dos distintos níveis de governo nos Estados Unidos, tal como fizemos no Gráfico 2 para o Brasil. Ao longo do século XX, percebese uma expressiva centralização, o que foi uma tendência mundial com o aumento de participação estatal. Essa última foi, em parte, impulsionada pela crise de 1929, pela ascensão do nazi-fascimo na década de 1930 e também da social-democracia do pós-II Guerra. No entanto, no período de expansão do ensino secundário público (ou seja, até 1940), vemos que estados e, principalmente, governos locais, possuíam grande autonomia financeira.

\section{Gráfico 3 - Receita Tributária nos Estados Unidos (Federal, Estadual e Local), 1902-1995.}

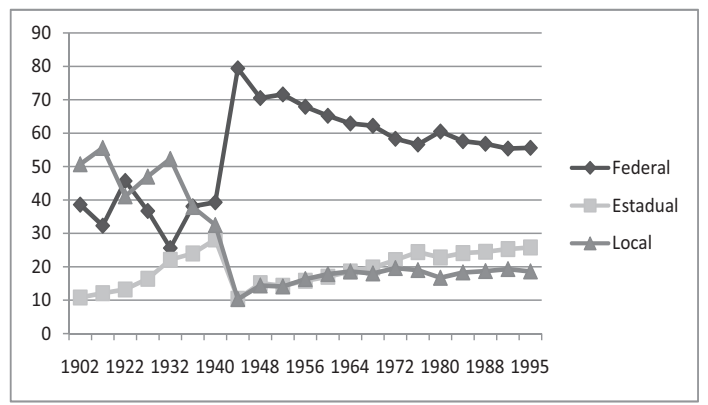

Fonte: Carter et al. (2006).

A receita tributária dos governos locais baseava-se em impostos sobre a propriedade. Ao contrário do que ocorreu no Brasil, essas fontes de financiamento eram suficientes para atender as crianças das localidades. Em 1932, havia 127.531 distritos escolares 
nos Estados Unidos, cuja grande maioria possuía autonomia tributária para arrecadar recursos para suas escolas (Goldin, 1999, p. 27). As receitas oriundas dos impostos sobre propriedade eram então diretamente direcionadas às escolas, de acordo com Goldin e Katz (2008) e Black e Sokoloff (2006, p. 95). A criação de escolas gerava um efeito positivo sobre os valores das propriedades próximas a uma escola com o decorrente aumento da demanda. De acordo com Goldin e Katz (2008), essa valorização refletia positivamente sobre as receitas que eram alocadas para a educação primária. Isso teria sido um efeito não intencional que garantiu o financiamento apropriado para a educação nos Estados Unidos. Pelo menos em parte, o avanço educacional norte-americano deveu-se ao sistema escolar financeiramente descentralizado e não capturado por elites.

\section{B. Estrutura dos Gastos em Educação}

A diferença entre as estruturas de gastos brasileira e norte-americana em níveis local e estadual foi bastante expressiva. Nos estados norte-americanos, os itens mais importantes na composição de gastos em 1961 eram educação, rodovias e saúde, sendo que 34,0\% dos gastos gerais estaduais eram relacionados à educação (Due, 1963, p.33-35). Por sua vez, os estados brasileiros, enquanto maiores responsáveis pela provisão de educação primária no país, despendiam cerca de $16,5 \%$ de seus gastos totais em educação em 1961, conforme pode ser visto no Gráfico 4:

Gráfico 4 - Percentual de Gastos Estaduais em Educação Pública, Brasil, 1941-1964.

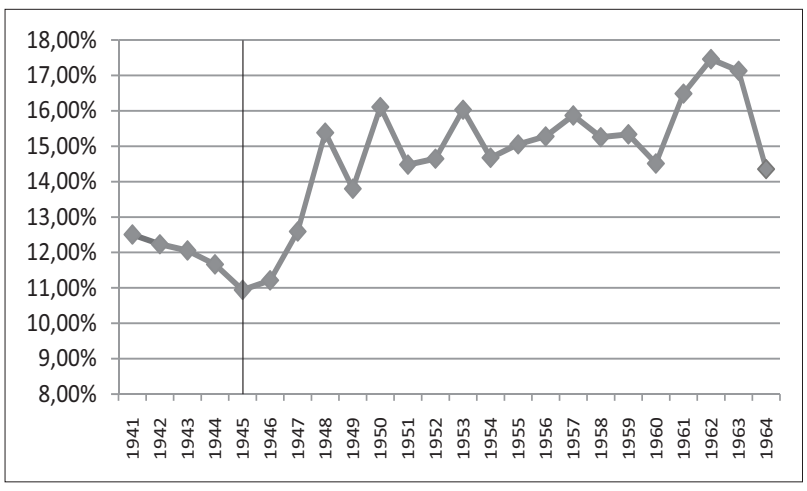

Fonte: BRASIL. Finanças do Brasil (vários números).

O Gráfico 4 mostra outro fenômeno importante: a tendência decrescente dos gastos estaduais em educação pública durante os primeiros anos da série é revertida após 1945 , 
mantendo-se acima dos 14\% a partir de 1950 (14,4\% em média com desvio-padrão de 1,9\% no período 1941-1964). Uma das causas dessa reversão é provavelmente a mudança institucional representada pela volta da democracia em 1945, com um regime menos centralizado do que o Estado Novo. Infelizmente, não dispomos de dados precisos sobre gastos estaduais antes de 1941.

O Gráfico 5 mostra como, mesmo no plano estadual, o gasto com educação pública foi percentualmente menor. Enquanto nos estados brasileiros cerca de 16,5\% de suas despesas totais eram destinadas à educação pública em 1961, esse percentual era de $34 \%$ dos gastos totais nos Estados Unidos. Também em saúde, outro item importante da oferta de bens públicos sociais, os gastos brasileiros eram proporcionalmente menores: $6,6 \%$ contra $21 \%$ dos norte-americanos.

\section{Gráfico 5 - Composição de Gastos dos Governos Estaduais: Brasil e Estados Unidos, 1961}

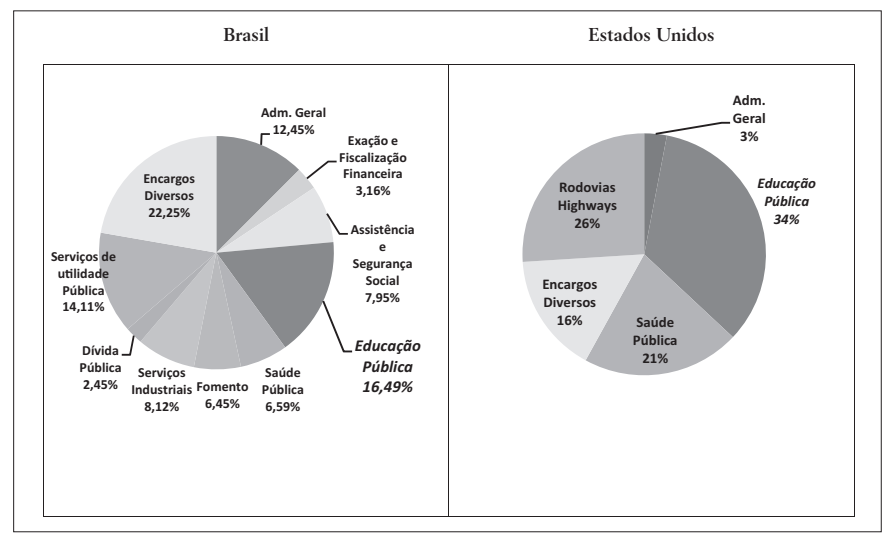

Fonte: Brasil. Ministério da Fazenda (1971) e Due (1963, p. 35).

Para o nível local, a diferença era maior ainda, o que torna nítida a diferença entre Estados Unidos e Brasil em termos de descentralização. O Gráfico 6 apresenta a discrepância que havia entre gastos educacionais e outros gastos no nível local, o que indica a prioridade da educação no plano dos governos locais dos Estados Unidos. Os municípios brasileiros, responsáveis historicamente por menos de $10 \%$ da arrecadação e dependendo da ajuda da União e dos estados, direcionavam apenas pouco mais do que $10 \%$ das suas despesas para a educação. Isso significa que, tanto em nível estadual como local, os Estados Unidos superavam substancialmente o Brasil em percentual de gastos no ensino. As estimativas para 1961 mostram que uma significativa parte dos gastos dos governos locais norte-americanos (45\%) era destinada à educação. 
Gráfico 6- Composição de Gastos dos Governos Municipais/Locais: Brasil e Estados Unidos,1961

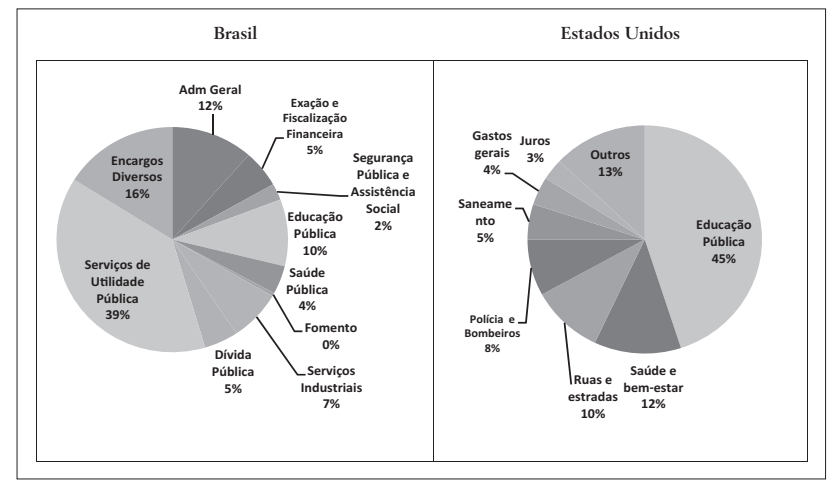

Fonte: Brasil. Ministério da Fazenda (1971) e Due (1963, p. 37).

Mesmo com o aumento da participação relativa dos gastos federais ao longo do século $\mathrm{XX}$, o que acompanhou uma tendência mundial, a situação financeira dos governos locais nos Estados Unidos mostrava-se muito melhor do que no Brasil, assim como também seu investimento em educação.

\section{Descentralização Administrativa e o Papel da União no Sistema}

A provisão das escolas estava a cargo dos estados no Brasil. Em alguns estados, como o Rio Grande do Sul, houve descentralização em favor dos municípios por decisão dos próprios governos estaduais (Moreira, 1954). Mesmo assim, as deficiências do financiamento apresentados por Melchior (1981), com parte significativa da receita tributária sob o poder do governo federal e sem repasses adequados para os níveis inferiores de governo, sugerem que o investimento em educação continuava a depender predominantemente dos governos estaduais.

A Tabela 1 mostra que, administrativamente, a maioria das escolas estava sob a responsabilidade dos estados em 1947 e 1962, de forma coerente com as atribuições constitucionais. Alguns estados descentralizaram administrativamente o ensino primário, deixando muitas escolas a cargo dos municípios, como o Rio Grande do Sul (69,8\% em 1947 e 70,9\% em 1962) e Maranhão (61,7\% em 1947 e 77,6\% em 1962): o primeiro com taxas de matrículas invejáveis de $63,5 \%$, enquanto que no último, apenas $22,8 \%$ das crianças estavam matriculadas em 1962. Por outro lado, estados como Amazonas e Espírito Santo tinham grande número de escolas sob administração estadual, apesar dos discrepantes resultados de matrículas: $36,8 \%$ e 54,9\% em 1962, respectivamente. Estados como o Ceará tiveram mudanças no período, passando de $31,8 \%$ das escolas 
de ensino primário fundamental administradas por municípios em 1947 para 67,3\% em 1962, assim como Piauí, que passou de 22,9\% para 53,7\%; Goiás, que passou de nenhuma escola municipal em 1947 para 37,4\% em 1962; e Paraná, que foi de 1,4\% em 1947 para 44,5\% em 1962. Alguns poucos estados aumentaram o percentual de escolas estaduais, como Santa Catarina e Minas Gerais.

Tabela 1- Percentagem de Escolas de Ensino Primário Fundamental sob a Responsabilidade Federal, Estadual, Municipal e Particular por Estados e Territórios da Federação, Brasil, 1947 e 1962

\begin{tabular}{|c|c|c|c|c|c|c|c|c|}
\hline \multirow{2}{*}{ Estados } & \multicolumn{4}{|c|}{1947} & \multicolumn{4}{|c|}{1962} \\
\hline & Federal & Estadual & Municipal & Particular & Federal & Estadual & Municipal & Particular \\
\hline Rondônia* & & 90,0 & & 10,0 & 94,4 & & & 5,6 \\
\hline Acre & & 60,7 & 32,8 & 6,6 & & 82,5 & 12,8 & 4,7 \\
\hline Amazonas & & 89,0 & & 11,0 & 0,1 & 96,0 & & 3,9 \\
\hline Roraima* & & 92,3 & & 7,7 & 87,2 & & & 12,8 \\
\hline Pará & & 94,0 & 0,1 & 5,9 & 1,9 & 61,2 & 28,4 & 8,5 \\
\hline Amapá* & & 100,0 & & & 81,7 & & 6,5 & 11,8 \\
\hline Maranhão & & 27,5 & 61,7 & 10,7 & & 11,1 & 77,6 & 11,3 \\
\hline Piauí & & 70,1 & 22,9 & 7,1 & & 36,9 & 53,7 & 9,4 \\
\hline Ceará & & 57,2 & 31,8 & 11,0 & & 23,1 & 67,3 & 9,7 \\
\hline R. G. do Norte & & 67,0 & & 33,0 & 0,1 & 39,2 & 43,1 & 17,7 \\
\hline Paraíba & & 81,4 & & 18,6 & 2,0 & 32,8 & 58,8 & 6,4 \\
\hline Pernambuco & & 16,7 & 53,8 & 29,5 & 0,7 & 18,5 & 61,7 & 19,1 \\
\hline Alagoas & & 31,6 & 45,6 & 22,8 & & 12,1 & 73,4 & 14,5 \\
\hline Sergipe & 0,1 & 58,9 & 23,2 & 17,7 & & 43,8 & 45,0 & 11,3 \\
\hline Bahia & & 74,5 & 15,5 & 10,0 & 0,1 & 37,2 & 54,1 & 8,6 \\
\hline Minas Gerais & & 21,6 & 71,7 & 6,8 & 0,3 & 36,4 & 58,6 & 4,7 \\
\hline Espírito Santo & & 95,2 & 0,7 & 4,1 & & 81,3 & 16,7 & 1,9 \\
\hline Rio de Janeiro & & 58,4 & 31,3 & 10,3 & 0,2 & 42,3 & 40,3 & 17,2 \\
\hline Guanabara** & & & 26,1 & 73,9 & & 34,8 & & 65,2 \\
\hline São Paulo & & 73,5 & 17,3 & 9,2 & & 74,6 & 20,6 & 4,8 \\
\hline Paraná & & 93,1 & 1,4 & 5,5 & & 52,5 & 44,5 & 3,0 \\
\hline Santa Catarina & & 56,4 & 41,7 & 1,9 & & 63,0 & 35,5 & 1,5 \\
\hline R. G. do Sul & 0,1 & 12,4 & 69,8 & 17,7 & 0,1 & 20,9 & 70,9 & 8,1 \\
\hline Mato Grosso & & 74,7 & 12,5 & 12,7 & & 75,1 & 15,7 & 9,1 \\
\hline Goiás & & 86,8 & & 13,2 & 0,4 & 52,8 & 37,4 & 9,5 \\
\hline D. Federal $* *$ & & & & & & & & 100,0 \\
\hline BRASIL & 0,0 & 49,9 & 37,1 & 13,0 & 0,5 & 43,6 & 47,2 & 8,6 \\
\hline
\end{tabular}

Fonte: IBGE. Anuários Estatísticos do Brasil (vários anos). NOTAS: *Territórios da Federação na época. **O Estado da Guanabara era Distrito Federal até 1960, quando a capital do país passa a ser Brasília. O Distrito Federal na tabela refere-se a Brasília. 
Como indicado na tabela, menos de $0,1 \%$ das escolas primárias eram federais. Estando as escolas primárias a cargo de estados ou municípios, as dificuldades fiscais desses níveis de governo e a ausência de repasses adequados dificultam a avaliação dos sistemas administrativos centralizados estaduais ou descentralizados municipais. Mesmo os estados mais progressistas tinham taxas de alfabetização e matrícula menores que a de países vizinhos como a Argentina: apenas 59,3\% dos paulistas, 58,6\% dos gaúchos e $56,6 \%$ dos catarinenses acima dos 5 anos de idade sabiam ler e escrever, de acordo com o Censo de 1950. Apenas 49,0\% dos brasileiros acima dos 15 anos eram alfabetizados, enquanto que $88 \%$ dos argentinos podiam ler e escrever em 1950 (Bergés, 2009, p. 28).

Durante o governo Vargas, o ministro Capanema, que esteve no cargo de 1934 a 1945 , afirmava que o financiamento do ensino básico deveria estar sob responsabilidade primordial dos Estados, justificando seu pouco empenho na questão da participação federal no ensino primário (Schwartzman; Bomeny; Costa, 2000; Rocha, 2000). O grande problema é que estados e municípios sempre tiveram dificuldades para arrecadar receitas. Mesmo considerando que a descentralização administrativa fosse benéfica, apenas a União tinha condições de financiar a educação adequadamente. Não obstante, o financiamento da educação primária foi colocado sob a responsabilidade dos outros níveis de governo, sem repasses adequados. Estados e municípios não possuíam recursos fiscais suficientes para arcar com os investimentos necessários em meio a outras prioridades, situação que perdurou com a volta da democracia após a queda do Estado Novo em 1945. Embora os escolanovistas advogassem a descentralização administrativa, eles defendiam a necessidade de maior participação da União devido à estrutura tributária vigente, a qual era muito mais favorável à União.

A longa demora pela aprovação das Leis de Diretrizes e Bases em 1961, que tramitou durante treze anos no Legislativo Federal, foi também responsável pela indefinição das diversas esferas do governo quanto a suas atribuições no campo da educação pública. Mascaro (1954, p. 144) também aponta a indefinição em torno do projeto da LDB como fator que desestimulou a cooperação entre as esferas de governo a fim de melhorar a situação. A incerteza institucional devido à falta de regulamentação do ensino provavelmente foi prejudicial para a expansão adequada do ensino, embora tenha havido crescimento das matrículas de 26,5\% em 1945 para 40,4\% em 1961, considerando a população de 5 a 14 anos. A descentralização administrativa sem provisões adequadas de recursos terminou sendo prejudicial para a educação brasileira, uma vez que não foram aproveitadas satisfatoriamente as vantagens de uma estrutura descentralizada, ao mesmo tempo em que os possíveis problemas da descentralização, como a desigualdade entre estados, também apareceram (Plank, 1996). 
A Tabela 2 indica que a ampla desigualdade educacional entre as regiões persistiu com a estrutura em vigor, embora nenhum estado de fato tenha atingido o nível de países desenvolvidos. A taxa de 70,2\% de escolarização nos estados mais desenvolvidos em 1958 para crianças dos 7 aos 11 anos ainda estava bem longe dos 99,5\% de crianças dos 7 aos 13 anos escolarizadas nos Estados Unidos no mesmo ano (Goldin, 1999, p. 42). Enquanto os estados do nordeste e norte-oeste apresentaram taxas de escolarização médias de $35 \%$, os estados do sul alcançaram o dobro da proporção de crianças frequentando a escola (Brasil. MEC, 1961, p. 12).

Tabela 2 - Taxas de Escolarização por Idades e por Regióes* no Brasil, 1958 (\%)

\begin{tabular}{ccccc}
\hline \multirow{2}{*}{ Idade } & \multicolumn{4}{c}{ Região } \\
\cline { 2 - 5 } & Norte-Oeste & Nordeste & Sul & Brasil \\
\hline 7 & 25,6 & 28,2 & 51,9 & 40,8 \\
8 & 34,8 & 36,1 & 74,0 & 56,4 \\
9 & 37,1 & 38,6 & 80,1 & 60,9 \\
10 & 40,3 & 40,3 & 80,4 & 62,1 \\
11 & 36,8 & 35,5 & 65,5 & 54,1 \\
\hline Total & 35,0 & 35,6 & 70,2 & 54,3 \\
\hline
\end{tabular}

Fonte: Brasil. MEC (1961, p. 12).

NOTA: *As regiões apresentadas pela tabela não são as regiões da nomenclatura tradicionalmente utilizada. A região Norte-Oeste da tabela consiste nos territórios (que correspondem aos atuais estados de Rondônia, Acre e Roraima) e nos estados do Amazonas, Pará, Maranhão, Piauí, Mato Grosso e Goiás. A região Nordeste da tabela consiste nos estados do Ceará, Rio Grande do Norte, Paraíba, Pernambuco. Alagoas, Sergipe, Bahia e Espírito Santo. A região Sul dessa tabela é formada por Minas Gerais, Rio de Janeiro, Guanabara, São Paulo, Paraná, Santa Catarina e Rio Grande do Sul.

A falta de apoio financeiro e administrativo federal na provisão de escolas públicas, aliada à falta de capacidade tributária dos estados e municípios, também foram determinantes do atraso educacional brasileiro no nível básico. Dada a estrutura tributária excessivamente centralizada, a falta de cooperação financeira adequada da União e a maldefinida descentralização, temos algumas das possíveis razões para o fracasso das políticas educacionais do período em termos comparativos internacionais.

\section{Poder Político, Sufrágio e a Falta de Interesse do Governo na Educação}

Ao longo deste trabalho, estivemos mais preocupados com os aspectos relacionados à descentralização. No entanto, esses aspectos não foram os únicos determinantes do 
atraso educacional brasileiro. Os relatórios presidenciais e as declarações de ministros mostram que pouco interesse havia por parte de governos em trazer melhorias. Como já mostramos em outros trabalhos com evidências empíricas mais contundentes (kang, 2009, 2010), além da centralização, o governo federal tinha outro motivo para não estar interessado em expansão da educação primária: a maioria da população estava excluída das eleições por ser analfabeta, mesmo durante o período democrático de 1945 a 1964. Em 1962, apenas 41,3\% da população acima dos 20 anos participou das eleições. Houve significativa melhoria na taxa de matrícula durante o período democrático, acompanhando o crescimento da participação eleitoral, no entanto insuficiente para acompanhar os demais países: cerca de $29 \%$ das crianças entre 5 a 14 anos estavam matriculadas no ensino primário fundamental comum em 1947, passando para 42\% em 1962.

O Gráfico 7 mostra como durante o Estado Novo, período politicamente mais fechado, houve queda da taxa de matrícula em relação à população total, revelando a pouca atenção dada pelo governo ao ensino primário. Após o retorno da democracia, há um aumento substancial da taxa de matrícula, mas a partir do início dos anos 1950, ocorre nova desaceleração. Embora a democracia tenha trazido certa melhora, ela foi restrita, impedindo que o país superasse seu atraso educacional relativo, uma vez que as políticas continuaram elitistas.

Gráfico 7 - Taxa de Matrícula no Ensino Primário Fundamental em Relação à População, Brasil, 1933-1959

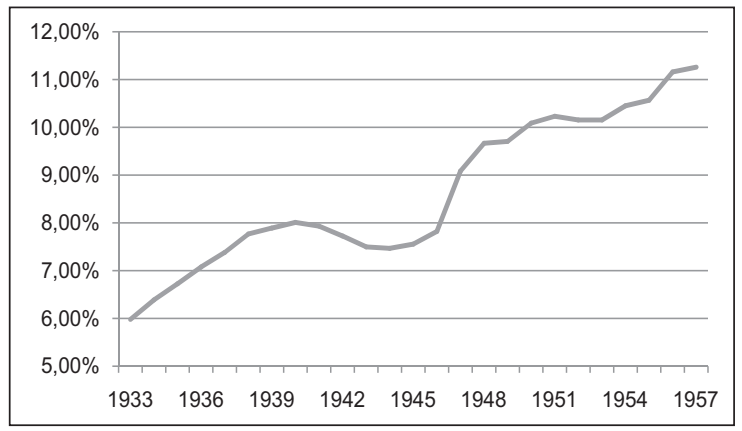

Fonte: IBGE - Anuários Estatísticos do Brasil, vários anos.

É possível que a hipótese de Hirschman (1980) seja adequada ao caso brasileiro. Uma vez que a elite possuía recursos para pagar escolas particulares a seus filhos, ao longo do tempo esses segmentos não tinham muitos incentivos para pleitear maior qualidade ou manutenção da qualidade existente das escolas públicas, que foram sendo abandona- 
das pelas elites à medida que a rede de escolas se expandiu: uma clara opção pela "saída". Assim, cada vez mais as escolas públicas de Ensino Fundamental, antes restritas a segmentos favorecidos, passaram a ser destinadas aos grupos sociais de menor renda. Tal situação minou a ação coletiva em favor de maior abrangência e qualidade do ensino público. Principalmente na década de 1950, a atuação do governo na educação primária foi limitada. O segundo governo Vargas, mesmo sob regime democrático, muito pouco fez pela educação, resumindo-se à criação de órgãos administrativos superiores como o CNPq e a CAPES em 1951. O governo de Juscelino Kubitschek lançou o Plano de Metas, que propunha metas para cinco setores: energia, transporte, indústrias de base, educação e alimentação. Ainda que a educação estivesse em pauta no programa, apenas $3,4 \%$ das verbas foram inicialmente previstas para a educação. O governo Goulart planejou aumento de verbas para a educação, que, no entanto, com a deposição do presidente em 1964, não se verificou.

Em resumo, o ensino primário foi deliberadamente desfavorecido desde 1930, principalmente nos governos de Vargas e Kubitschek, tendo sido os ensinos secundário e superior privilegiados durante praticamente todo o período que se estendeu até 1964. O que apresentamos até aqui parece ser suficiente para demonstrar que, em nível federal, as políticas implementadas tenderam a ser elitistas. Essa conclusão sugere que o maior interessado na questão, o segmento populacional majoritário que não fazia parte da elite, não foi capaz de pressionar de maneira efetiva o governo federal em favor da ampliação dos serviços educacionais entre 1930 e 1964.

No final do século XX, por outro lado, com a extensão do direito de voto aos analfabetos em 1988 e a implementação do Fundo de Manutenção e Desenvolvimento do Ensino Fundamental e de Valorização do Magistério (FUNDEF) em 1998, que reservou recursos para o Ensino Fundamental, houve significativa expansão de matrículas nesse nível de ensino, chegando quase à universalização. Além disso, houve maior enforcement das regras de aplicação de recursos no Ensino Fundamental. É bastante provável que o avanço educacional tenha ocorrido por conta dessas duas mudanças institucionais. ${ }^{8}$

No entanto, essa não era a situação no período aqui estudado, em que o voto era restrito e o financiamento era escasso. Assim como no caso indiano estudado por Lindert, em várias ocasiões, as ações tomadas pelo governo federal foram deliberadamente favoráveis à persistência da desigualdade no acesso à educação elementar, mesmo no

\footnotetext{
${ }^{8}$ Evidências do papel positivo do FUNDEF podem ser encontradas em Menezes-Filho e Pazello (2007), que destacam o aumento do salário relativo dos professores da rede pública e consequente melhoria na proficiência dos alunos. Mello e Hoppe (2005) mostram que o aumento das matrículas no Brasil na década de 1990 teria relação com a implementação do FUNDEF e maior enforcement devido à criação de mecanismos como os "Conselhos de Acompanhamento e Controle Social do FUNDEF". O FUNDEF também teria incentivado a descentralização e o aumento dos gastos por estudante. Em suma, a importância do FUNDEF teria sido a remoção de parte das restrições de oferta de educação.
} 
período democrático 1945-1964. O país continuou atrasado em termos de matrículas em relação ao resto do mundo, uma vez que o regime era parcialmente democrático, excluindo os analfabetos do processo eleitoral. O Brasil tinha uma espécie de democracia elitista entre 1945 e 1964, se tentarmos aplicar o conceito de Lindert (2004). Deparando-se com uma estrutura financeira centralizada e sem acesso às urnas, a população não tinha meios para pleitear escolas públicas adequadas e expansão de matrículas. Em muitos lugares, a expansão do sufrágio precedeu e causou a expansão educacional (Engerman; Sokoloff, 2005; Goldin; Katz, 2008), mas no caso brasileiro, poucos podiam de fato votar. A maioria da população não tinha acesso às instituições que permitiriam mudanças efetivas no ensino em favor das massas.

\section{Considerações Finais}

Examinamos neste trabalho como era a estrutura educacional no Brasil principalmente a partir dos anos 1930 até 1964, comparando-a com a dos Estados Unidos no seu período de expansão de matrículas, que começou em meados do século XIX e foi até a década de 1940, quando terminou o processo de massificação do ensino secundário nos Estados Unidos. Comparamos períodos diferentes da história dos dois países porque o período entre 1930 e 1964 foi uma fase de mudanças profundas na sociedade brasileira, com intensa industrialização e crescimento acelerado com participação estatal. Era, portanto, uma oportunidade ímpar de se investir em educação básica, o que poderia ter gerado benefícios enormes para a economia brasileira no longo prazo, uma vez que educação é uma das bases para o crescimento sustentado.

Vimos que esse período, durante o qual poderiam ter sido realizados investimentos educacionais de grande amplitude, foi também um período em que houve maior centralização política e administrativa. Mostramos, contudo, que o governo federal, que concentrava a maior parte dos recursos fiscais, não realizou maiores esforços para a melhoria do ensino primário no Brasil durante o período em questão. Além disso, também foi visto que o Brasil atendia algumas das condições de igualdade de oportunidades educacionais consideradas por Goldin e Katz para o caso norte-americano. Em alguns estados, havia descentralização administrativa, como no caso do Rio Grande do Sul e no Maranhão. Entretanto, muitos outros aspectos considerados importantes pela literatura não estavam presentes. Nos Estados Unidos, as localidades tinham autonomia financeira e despendiam grande parte de seus recursos nas escolas, mesmo quando houve maior centralização das receitas tributárias a partir dos anos 1940. Já no Brasil, em geral, havia centralização com a delegação de funções administrativas aos estados, mas não às localidades, sem contar a forte dependência fiscal das municipalidades em relação aos estados e à União. Os municípios brasileiros não possuíam meios de gerar 
receitas para a educação mediante a criação de novos tributos. Por isso, a contribuição da União seria crucial, se consideramos como dada a estrutura tributária. Não obstante, os governos federais relutaram em transferir recursos aos outros níveis de governo, os quais acabaram se responsabilizando pelo ensino primário sem contar com fontes adequadas de financiamento - tanto pela crença de que o governo deveria priorizar o ensino superior, como pelos desvios gerados por anos de indefinição quanto à verdadeira atribuição dos diversos níveis de governo no que se refere à educação.

No que se refere à descentralização, ela pode ser um fator fundamental de expansão da escolaridade quando não há captura dos governos locais por parte de elites ou grupos poderosos. A descentralização pode em tese aumentar a voz política da população. Se houver captura, no entanto, a descentralização tende a levar à diminuição da voz política da maioria da população. O nível de captura depende das instituições e do poder político local. Nesse caso, é bem razoável supor que a descentralização seja bemsucedida em locais em que as instituições são mais igualitárias. Para sabermos se maior descentralização teria sido benéfica, é necessário novamente considerar a hipótese de origens coloniais e instituições (Engerman; Sokoloff, 1997, 2002).

Além disso, vimos rapidamente que outro motivo para a educação não ter se expandido tem a ver com a limitada participação eleitoral da população. Significativa parcela da população não tinha direito de voto por ser analfabeta, mesmo no período democrático 1945-1964. A maioria da população não apenas não tinha poder decisório na administração das escolas, como também não podia pleitear por expansão educacional via voto. Desse modo, não havia motivos para a elite política se preocupar com a expansão do ensino primário e, por isso, a educação básica nunca foi prioridade dos governos. De qualquer maneira, vimos que a descentralização ocorrida na maior parte do Brasil prescindiu de fontes de financiamento, havendo também indefinição das atribuições de cada nível de governo na administração e financiamento escolar, o que gerou incerteza institucional, possibilidade de desvios de recursos e péssimo desempenho na expansão de matrículas em termos comparativos. A ausência de financiamento parece ter sido também fator crucial para o atraso educacional em outros países como Índia, também caracterizado por privilegiar o Ensino Superior. Como afirma Lindert:

Na transição para a autonomia provincial indiana nos anos 1930 e 1940, a maioria das províncias aprovou leis de educação compulsória. No entanto, na ausência de financiamento e enforcement, essas leis não foram mais efetivas na Índia do que em qualquer outro lugar onde a obrigatoriedade tentou preceder a demanda privada por educação de massas (Lindert, 2003, p. 337). ${ }^{9}$

\footnotetext{
9 "In the transition to Indian provincial autonomy in the 1930 s and 1940 s, most provinces passed compulsory education laws. But in the absence of funding and enforcement, these were no more effective in India than in
} 
Essa descrição parece ser bastante similar à experiência brasileira analisada neste trabalho. Assim como na Índia, a situação precária atual da educação primária brasileira pode ser explicada, via path dependence, pelo processo histórico de expansão educacional no Brasil. Esse processo foi lento e desigual, em boa parte, devido à ausência de fontes adequadas de financiamento e à falta de voz política da população.

\section{Referências}

Astorga, P., Bergés, A., Fitzgerald, V. (2005), The standard of living in Latin America during the Twentieth Century. Economic History Review. v. 58, n. 4, p. 765-796, nov.

Baiocchi, G. (2005), Inequality and innovation: decentralization as an opportunity structure in Brazil. In: Bardhan, P., Mookherjee, D. Decentralization and Local Governments in Developing Countries: A Comparative Perspective. Cambridge, MA: MIT Press.

Barbosa, R. (1883), Obras completas, v. 10. Rio de Janeiro: Ministério da Educação e Saúde, 1947.

Bardhan, P. (2002), Decentralization of governance and development. Journal of Economic Perspectives, v. 16, p. 185-205.

Bardhan, P., Mookherjee, D. (2000), Capture and governance at the local and national levels. American Economic Review, v. 90, n. 2, p. 135-9.

Bardhan, P., Mookherjee, D. (2006), Decentralization, corruption, and government accountability: an overview. In: Rose-Ackerman, S. International Handbook on the Economics of Corruption. Cheltenham: Edward Elgar Publishing.

Barro, R., Lee, J.-W. (2000), International data on educational attainment: updates and implications. CID Working Paper No. 42, April.

Bergés, A. (2009), Vertical and horizontal inequalities in human capital: educational attainment and literacy in Latin America during the Twentieth Century. Apresentado na mini-conferência A Comparative Approach to Inequality and Development: Latin America and Europe, Fundácion Ramón Areces and Instituto Figuerola. Madrid, 8-9 Maio.

Black, S., Sokoloff, K. (2006), Long-term trend in schooling: the rise and decline (?) of public education in the United States. In: Hanushek, E.; Welch, F. (org.), Handbook of the Economics of Education, p. 69-105.

Brasil. (1916), Diretoria Geral de Estatística - DGE. Estatística da Instrucção. Rio de Janeiro: Typographia da Estatistica.

Brasil. (1961), MEC. Comentários sobre o Ensino Primário. Rio de Janeiro: MEC.

Brasil. (1952), Ministério da Fazenda. Finanças do Brasil: receitas e despesas - União, estados e municípios: exercícios de 1941-1950, v. 18. Rio de Janeiro, S.N.

Brasil. (1971), Ministério da Fazenda. Finanças do Brasil: receitas e despesas - União, estados e municípios: exercícios de 1951-1964, v. 21. Rio de Janeiro, S.N.

Bueno, L. F., Pastore, A. C., Gitelman, C. (1962), Aspectos Gerais da Receita Pública no Brasil. São Paulo: s.n.

Burki, S. J., Perry, G. E., Dillinger, W. R. (1999), Beyond the Center: Decentralizing the State. Washington D.C.: World Bank.

Carter, S. B. et al. (eds.), (2009), Historical Statistics of the United States, Millennial Edition Online. Cambridge: Cambridge University Press, 2006. Disponível em <http://hsus.cambridge.org/>. Acesso em 26 Jun.

Chaudhuri, S. (2005), What difference does a constitutional amendment make? The 1994 Panchayati Raj Act and the attempt to revitalize rural local government in India. In: Bardhan, P.; Mookherjee, D. (eds.). Decentralization and Local Governments in Developing Countries: A Comparative Perspective. Cambridge, MA: MIT Press.

Drezè, J., Saran, M. (1995), Primary education and economic development in China and India: overview and two case studies. In: Basu, K. et al. (eds.). Choice, Welfare, and Development: A Festschrift in Honour of Amartya K. Sen. Oxford: Clarendon Press, p. 182-241.

Due, J. (1963), Government Finance: an economic analysis. 3rd ed. Homewood: R. D. Irwin.

any other polity where unfunded compulsion tried to precede the private demand for mass schooling" (Lindert, 2003, p. 337). 
Dulles, J. W. F. (1969), The contribution of Getulio Vargas to the modernization of Brazil. In: Baklanoff, E. (ed.) The Shaping of Modern Brazil. Baton Rouge: Lousiana State University Press.

Engerman, S., Sokoloff, K. (1997), Factor endowments, institutions, and differential paths of growth among new world economies: a view from economic historians of the United States. In: Haber, S. (org.). How Latin America Fell Behind. Stanford: Stanford University Press, p. 260-304.

Engerman, S., Sokoloff, K. (2002), Factor endowments, inequality, and paths of development among new world economies. National Bureau of Economic Research - Working Paper No. 9259, out.

Fausto, B. (1986), A Revolução de 1930. 10 ed., São Paulo: Brasiliense.

Fogel, R. W. (1964), Railroads and American economic growth: essays in econometric history. Baltimore: Johns Hopkins University Press.

Fogel, R. W. (1967), The specification problem in economic history. Journal of Economic History, v. 27, n. 3, p. 283-308, set.

Fonseca, P. C. D. (1989), Vargas: o capitalismo em construção. São Paulo: Brasiliense.

Frankema, E. (2008), The historical evolution of inequality in Latin America: a comparative analysis, 1870-2000. Tese (Doutorado em Economia), Rijksuniversiteit Groningen.

Galasso, E., Ravaillon, M. (2001), Decentralized targeting of an anti-poverty program. Development Research Group Working Paper, World Bank, Washington D.C.

Goldin, C. (1999), A brief history of education in the United States. NBER Historical Paper, ago.

Goldin, C., Katz, L. (2008), The race between education and technology. Cambridge, MA: Harvard University Press.

Ianni, O. (1971), Estado e planejamento econômico no Brasil, 1930-1970. Rio de Janeiro: Civilização Brasileira.

Instituto Brasileiro De Geografia E Estatística - IBGE. Anuários Estatísticos do Brasil, vários números. Rio de Janeiro: IBGE.

Kang, T. H. (2009), Education, political power, and development in Brazil, 1930-1964. Apresentado no XV World Economic History Congress, Utrecht.

Kang, T. H. (2010), Instituições, voz política e atraso educacional no Brasil, 1930-1964. Dissertação de Mestrado (Economia), FEA-IPE-USP.

King, E., Özler, B. (1998), What's decentralization got to do with learning? The case of Nicaragua's school autonomy reform. Development research group working paper, World Bank, Washington D.C.

Lindert, P. H. (2003), Voice and growth: Was Churchill right? Journal of Economic History, v. 63, n. 2, p. 315-350, jun.

Lindert, P. H. (2004), Growing public: social spending and economic growth since the eighteenth Century, v. 1. Cambridge: Cambridge University Press.

Maduro, P. R. (2007), Taxas de matrículas e gastos em educação no Brasil. Dissertação (Mestrado em Economia), Escola de Pós-Graduação em Economia da Fundação Getúlio Vargas, Rio de Janeiro.

Mascaro, C. C. (1954), Município e ensino no estado de São Paulo. São Paulo.

Melchior, J. (1981), A política de vinculação de recursos públicos e o financiamento da educação no Brasil. São Paulo: Universidade de São Paulo, Faculdade de Educação.

Mello, L., Hoppe, M. (2005), Education attainment in Brazil: the experience of FUNDEF. OECD Economics Department Working Papers no. 424.

Menezes-Filho, N, Pazello, E. (2007), Do teachers' wages matter for proficiency? Evidence from a funding reform in Brazil. Economics of Education Review, v. 26, p. 660-672.

Moreira, J. R. (1954), A escola elementar e a formação do professor primário no Rio Grande do Sul. Rio de Janeiro: INEP.

Nagle, J. (1974), Educação e sociedade na Primeira República. São Paulo: EPU; Rio de Janeiro: Fundação Nacional de Material Escolar.

Oates, W. E. (1972), Fiscal federalism. New York: Harcourt Brace Jovanovich.

Pires, J. M. (1996), A politica social no periodo populista. São Paulo: IPE-USP.

Plank, D. N. (1996), The means of our salvation: Public Education in Brazil, 1930-1995. Vestview Press.

Probe Team. (1999), Public report on basic education in India. New Delhi: Oxford University Press.

Rocha, M. B. M. (2000), Educação conformada: a politica de educação no Brasil, 1930-1945. Juiz de Fora: Ed. UFJF.

Romanelli, O. (1987), História da educação no Brasil, 1930-1973. 9 ed. Petrópolis: Vozes. 
Santos, B. S. (1998), Participatory budgeting in Porto Alegre: toward a redistributive democracy. Politics and Society, v. 26 , n. 4 , p. 461-510.

Saviani, D. (2008), História das idéias pedagógicas no Brasil. 2 ed. Campinas: Autores Associados.

Schwartzman, S., Bomeny, H., Costa, V. M. R. (2000), Tempos de Capanema. 2 ed. São Paulo: Paz e Terra/FGV.

Skidmore, T. (1973), Politics and economic policy making in authoritarian Brazil, 1937-1971. In: Stepan, A. (ed.), Authoritarian Brazil. New Haven: Yale University Press.

Sodré, N. W. (1976), História da burguesia brasileira. Rio de Janeiro: Civilização Brasileira.

Souza, A. M. (1979), Financiamento da educação e acesso à escola no Brasil. Rio de Janeiro: IPEA/INPES.

Suzigan, W. (1976), As empresas do governo e o papel do estado na economia brasileira. In: Silva, F. R. et al. (eds.) Aspectos da participação do governo na economia. Rio de Janeiro: IPEA/INPES.

Teixeira, A. (1956), Educação e a crise brasileira. São Paulo: Nacional.

Tendler, J. (1997), Good government in the tropics. Baltimore: John Hopkins University.

Tommasi, M., Weischelbaum, F. (1999), A principal-agent building block for the study of decentralization and integration. Working Paper n. 20, Department of Economics, Universidad de San Andrés.

Topik, S. (1980), State interventionism in a liberal regime: Brazil, 1889-1930. Hispanic American Historical Review, 60 (4), p. 593-616.

Topik, S. (1987), A presença do estado na economia política do Brasil: de 1889 a 1930. Rio de Janeiro: Record.

World Bank. (2000), Entering the twenty-first century. Oxford and New York: Oxford University Press. 